\title{
PROVÁVEIS INFLUÊNCIAS DO PRIMEIRO ANO DO CURSO DE SECRETARIADO EXECUTIVO BILÍNGUE NO COTIDIANO DOS ESTUDANTES
}

\section{PROBABLE CONTRIBUTIONS AND IMPACTS OF THE FIRST ACADEMIC YEAR OF THE EXECUTIVE BILINGUAL GRADUATION COURSES ON THE STUDENT'S ROUTINE}

\section{Cibele Barsalini Martins}

Doutoranda em Administração pelo Programa de Mestrado e Doutorado em Administração da Universidade Nove de Julho - UNINOVE cibelebm@uol.com.br

\section{Luiz Antônio Genghini}

Mestre em Administração pelo Programa de Mestrado da Universidade de Guarulho - UNG, Professor da Universidade Paulista - UNIP lagenghini@hotmail.com

\section{Ismar Vicente}

Doutorando em Administração pelo Programa de Mestrado e Doutorado em Administração da Universidade Nove de Julho - UNINOVE.

ismar@uol.com.br

\section{Penha Maria Mendes Terra}

Especialista em Qualidade nas Organizações, Professora e Coordenadora do Curso de Secretariado Executivo Bilíngue da Universidade Paulista - UNIP penha.terra@uol.com.br 


\section{RESUMO}

Neste artigo os autores têm como objetivo identificar as influências do primeiro ano do curso de Secretariado Executivo Bilíngue no cotidiano dos alunos. Para tanto, abordam-se as questões relacionadas à evolução nos aspectos profissional, social e individual, segundo os parâmetros das diretrizes curriculares das Instituições de Ensino Superior, emitida pelo Ministério de Educação e Cultura - MEC. Utilizou-se para tanto o método de pesquisa exploratório, não probabilístico por conveniência, julgamento e cotas. Como principais pressupostos teóricos foram abordados os conceitos sobre a escolha do curso superior e as possibilidades de entrar no mercado de trabalho. Os resultados do estudo apontam que os alunos em Secretariado Executivo vêm participando, efetivamente, do mercado de trabalho e possuem consciência da necessidade de constante aperfeiçoamento educacional e objetivam melhorar, cada vez mais, sua qualificação profissional.

Palavras-chave: Secretariado Executivo; Escolha; Aferição; Influências; Alunos; Cotidiano. 


\section{ABSTRACT}

The objective of this article is to identify the influence of Bilingual Executive Secretary course in the first year of students' life. For this purpose, the approach utilizes questions related to professional, social and individual development according to curriculum guiding standards for Graduation Institutions set forth by Brazilian Education and Culture Ministry (MEC). The method used was a non-probabilistic explanatory research that was conveniently chosen, judged, and set in quotas. Main theoretical basis were concepts discussed about choosing courses for obtaining a degree as well as possibilities of entering work market. The main results point out that students of an Executive Secretary Course are effectively taking part of work market and are conscious of constant need for educational improvement aiming a better professional qualification.

Key words: Secretary Executive; Choise; Research; Directrix; Influences; Students; Daily. 


\section{INTRODUÇÃo}

Alves (2007), educador, escritor, psicanalista e professor emérito da Unicamp, conclui sua crônica intitulada "Não é próprio falar sobre alunos..." dizendo que sonha com o dia em que os professores, falarão menos sobre os programas e pesquisas e terão mais prazer em falar sobre os seus alunos. Este é o mote neste trabalho, que versa sobre alunos, seus processos e seus destinos no mundo que está além dos muros da universidade e que é composto por vivências sociais e profissionais, analisando especificamente o efeito dos processos vivenciados no primeiro ano do curso de Secretariado Executivo Bilíngue sobre o cotidiano dos alunos, apontando experiências e evolução.

Durante muitos séculos a humanidade sobreviveu sob a luz de sistemas altamente conservadores, em ciclos evolutivos muito longos, de modo que viver era, praticamente, uma questão de adaptar-se ao tempo e assimilar os costumes.

Entretanto, a "cultura do consumo", consequência da Revolução Industrial e Comercial, conduziu a sociedade moderna a entender que, segundo Slater:

Os consumidores são indivíduos particulares procurando
racionalmente satisfazer os interesses por eles mesmos definidos
por meio de um mecanismo (o mercado) que coordena em
sociedade a ação dos indivíduos, sem comprometer a autonomia de
suas escolhas (SLATER, 2002, p. 49).

Assim sendo, a partir do século XVIII e mais especificamente no século $X X$, o indivíduo é tangido a encarar novas situações, decorrentes da indústria e do comércio. A tendência parece se aprofundar ainda mais no início do século XXI devido ao agravamento das instabilidades econômicas e sociais que sempre se refletem no mercado de trabalho, objetivo primeiro de todos os estudantes.

As novas situações, que transferem o equilíbrio econômico das nações para as cidades e para a indústria, passam a demandar mão de obra especializada ao mesmo tempo em que oferecem mais opções de conforto e lazer, introduzidas pela sociedade de consumo, em contraposição à concorrência e à volatilidade

Revista de Gestão e Secretariado, São Paulo, v. 1, n. 2, p. 53-77, jul./dez. 2010. 
das oportunidades no ambiente profissional.

Durante o século $X X$, o sistema evoluiu e nos encontramos atualmente a observar uma sociedade altamente desenvolvida tecnicamente, gerando menos empregos do que deveria e instigando os indivíduos ao consumo maior do que suas posses, em clima de permanente competição.

Os aspectos relativos às mudanças são constatados por Andrade, Coordenador de relatório do MEC.

A atual revolução tecnológica, distintamente da primeira revolução industrial, que teve o mérito de substituir a força física do homem pela energia mecânica, caracteriza-se por ampliar a capacidade intelectual humana na produção. A nova forma de organização exigirá do trabalhador qualidades de natureza não apenas operacional como também conceitual. (MEC, 1999, p.6).

Diante deste contexto verifica-se o aumento da procura por qualificação profissional, uma vez que o mercado passou a exigir mais preparo dos empregados para que consigam operar sistemas e equipamentos mais complexos em busca de produtividade e de qualidade.

Neste sentido, estudos de Alonso (2002) constatam que a profissão de secretariado executivo vem sofrendo mudanças ao longo do tempo e, atualmente, o profissional que desempenha a profissão de secretariado executivo deve adaptar-se ao novo perfil exigido pelo mercado de trabalho, as determinações da lei e do código de ética que regulamentam a profissão. Uma das exigências para este profissional conseguir exercer esta função é a dedicação que ele deve ter para conhecer as novas tecnologias, instrumentos que tornem seu trabalho mais eficiente, a ética profissional e a formação superior na área.

No presente trabalho, os autores analisam as influências do primeiro ano do curso de secretariado executivo bilíngue no cotidiano dos estudantes a fim de verificar se o ingresso na universidade e a prática das atividades acadêmicas interferiram diretamente na evolução profissional dos alunos em suas relações profissionais no mercado de trabalho.

Revista de Gestão e Secretariado, São Paulo, v. 1, n. 2, p. 53-77, jul./dez. 2010. 


\title{
2 PROBLEMA DA PESQUISA
}

Partindo deste contexto é analisado o status quo dos alunos do primeiro ano do curso de Secretariado Executivo Bilíngue em quatro unidades de uma universidade particular do estado de São Paulo, no ano letivo de 2006, considerando os processos que os conduziram ao curso e os efeitos deste sobre eles ao final do primeiro ano letivo. As quatro unidades são: Vergueiro (São Paulo), Chácara Santo Antônio (São Paulo), São José dos Campos e Sorocaba.

Além de servir para conhecer com mais assertividade a realidade dos alunos, os resultados servem também para que as escolas considerem outras variáveis importantes, como, por exemplo, o relacionamento com seu público interno nas ações de marketing e comunicação. Sobre a comunicação com o público interno nas ações de marketing Genghini e Derito entendem que:

\begin{abstract}
O marketing interno ou endomarketing continua importante, muito menos como um fator contribuinte para a implantação de mudanças e muito mais como um agente auxiliar na composição de procedimentos adaptados aos novos paradigmas de gestão, treinando, capacitando e induzindo equipes a novo comportamento, novas atitudes e novas posturas, sintonizadas com os objetivos da organização a que servem.(GENGHINI, DERITO, 2002, p. 70).
\end{abstract}

Diante da complexidade da situação, envolvendo vários intervenientes elaborouse a presente pesquisa para verificar junto aos alunos do primeiro ano do curso de secretariado executivo bilíngue, com a finalidade de responder à pergunta inspiradora do título: Quais são as prováveis influências do primeiro ano do curso de secretariado executivo bilíngue no cotidiano dos estudantes?

Como não se desconhece que o ingresso na universidade expõe os estudantes a um processo de escolha quase sempre difícil, antes de apresentar os dados da pesquisa propriamente dita, exploram-se um pouco os aspectos relacionados à escolha do curso.

Revista de Gestão e Secretariado, São Paulo, v. 1, n. 2, p. 53-77, jul./dez. 2010. 


\section{O PROCESSO DA ESCOLHA}

As mudanças produzidas pela indústria e pelo comércio criaram novas necessidades e passaram a exigir que os cidadãos se preparassem mais para competir pela sobrevivência e pela evolução profissional. O universo das profissões vem mudando radicalmente e funções milenares estão sendo extintas cedendo lugar a novas atividades.

Esta nova realidade está possibilitando o surgimento natural de uma grande oferta de cursos, escolas e universidades com propostas para preparar melhor o indivíduo para este cenário.

O novo cenário de mudanças velozes e de necessidade constante de adaptações criou um novo indivíduo, com dificuldade de adaptação, chamada segundo Moreira e Oliveira (2002, p. 2) de "analfabetismo funcional", que está relacionado com a dificuldade do leitor de entender textos de vários tipos na sociedade da informação, onde a palavra escrita e os símbolos, em geral, são usados intensivamente.

Embora as ofertas de capacitação passaram a ser amplas na tentativa de acompanhar a demanda, o processo de escolha da estratégia a ser adotada pelo indivíduo foi-se tornando uma atividade cada vez mais solitária e estressante.

Capacitação para o trabalho, segundo Mattar (2002) não é uma forma de qualificar tecnicamente os indivíduos, mas um instrumento de ajuda na articulação dos trabalhadores, de estímulo ao pensamento crítico sobre o mundo do trabalho e suas formas de organização e de aquisição de cidadania, que se obtém por meio de exercícios e práticas decorrentes da absorção de informações teóricas e da atualização a respeito de novas práticas profissionais.

Por volta de 1640, Musashi, o maior dos Samurais (2002, p. 46), já ensinava: "É muito difícil que se chegue a compreender o verdadeiro Caminho $(\ldots)^{\prime \prime}$, afirmando mais à frente (p. 52) que "O homem tem de dar polimento ao Caminho que escolheu". Bronson (1994, p. 19) desenvolve um longo discurso na tentativa de apresentar resposta à pergunta: "Você está onde queria estar?", e

Revista de Gestão e Secretariado, São Paulo, v. 1, n. 2, p. 53-77, jul./dez. 2010. 
Shinyashiky (2001, p. 24), ao referir-se ao clima de hipercompetição instaurado no final do século XX e no início do século XXI, ensina que "Todo mundo acha desagradável trabalhar em regime de competição, porém ele cada vez mais faz parte da nossa vida".

Macedo (1998) publica um livro para tentar estruturar um roteiro destinado a facilitar o processo de escolha por parte dos candidatos a conseguir uma profissão por meio do ensino universitário. Suas indicações vão desde sugestões sobre a vocação passando pelos processos de orientação vocacional, busca de informações, encaminhamento, autoconhecimento e contatos com o mercado por intermédio de profissionais, de literatura, da imprensa e de visitas pessoais, com a finalidade de realizar a escolha mais acertada, sugerindo a construção de uma rede ou network.

A época da escolha tende a ser muito mais importante do que parece porque o indivíduo se vê obrigado a abandonar a psicologia do entitlement, segundo Bardwick (1998, p. XV), "Um modo de encarar a vida", onde "Aqueles que a assumem acreditam que não têm de fazer jus àquilo que recebem", tendo de mudar o comportamento, passando a decidir, adotar posturas e ter atitudes coerentes com a nova situação, decorrente da escolha feita, para evitar a desmotivação, o desinteresse e a desistência. Segundo ensina Gil (1994, p.56) "É indiscutível a importância da motivação na aprendizagem. Um aluno pode ser inteligente, mas, se ele não quer aprender, ninguém poderá fazê-lo aprender".

Júlio (2002, p. 5) lembra que "Por vezes, nos sentimos perdidos num mar de informações que não chegam a se transformar em conhecimento", e que cada indivíduo possui um patrimônio pessoal que é "a capacidade de perceber aquilo que realmente importa, nas cores apropriadas, à luz das circunstâncias (p. 21)" e que "Esse processo, pleno de subjetividade, resulta de uma análise comparada de fatos, ambientes, conjunturas e dos personagens implicados" (p. 21).

A diversidade de variáveis e a pressão pela mudança tendem a criar um processo tenso onde os indivíduos passam a lidar com os medos e as incertezas, mas assumindo o risco da mudança tomam decisões. Olsen (1994, p. 11) diz que os antigos marinheiros indicavam 0 desconhecido com anotações nas margens dos mapas com a inscrição: "Aqui pode haver dragões", soando como 
um alerta do perigo e ao mesmo tempo como um desafio à incerteza, limite que só os mais ousados ultrapassariam, encarando a possibilidade do novo como desafio à mudança, vislumbrando oportunidades onde outros viam problemas e dificuldades.

No momento em que se trabalha este texto, o público sondado já ultrapassou a fase de escolha e a proposta é, justamente, aferir os efeitos da escolha sobre a vida pessoal e profissional, depois de um ano no curso de Secretariado Executivo Bilíngue.

\section{A EVOLUÇÃO DO ANO LETIVO}

Pode-se assegurar que para os professores, apesar das eventuais dificuldades, o convívio com os alunos de primeiro ano é altamente denso e enriquecedor porque é um período de adaptação, onde coabitam a euforia, a ansiedade, as descobertas, os avanços e as frustrações.

Salas de aula de primeiro ano são ambientes instáveis e em constante reorganização, conforme ensina Rifkin:

Nunca antes, na história, a humanidade esteve tão despreparada para os novos desafios, riscos e oportunidades tecnológicas e econômicas que se avizinham no horizonte [e que] Nosso modo de vida está para se transformar nas próximas décadas mais profundamente que nos últimos milhares de anos (RIFIKIN,1999, p.1).

O efeito da velocidade das mudanças já está a demandar dos professores, novas posturas pedagógicas no relacionamento com seu público, deixando de tentar ensinar o que e como fazer para passar a incentivar a pesquisa, a criatividade e a inovação, partindo do conhecimento disponível em função do encurtamento dos ciclos de mudanças e das facilidades com que os modelos se tornam obsoletos.

$\mathrm{Na}$ busca de seus objetivos, na tentativa de realizar seus planos e na contingência das possibilidades e limitações, os alunos são incentivados a iniciar o processo de identificação e acesso ao conhecimento de modo a tirar as 
próprias conclusões e a gerar os modelos de soluções adequados à situação e ao problema específico que encaram, evoluindo, segundo Barnard (1971 p. 50), para "uma ação efetiva, se ela cumpre seu objetivo específico".

Ao aferir os efeitos do primeiro ano do curso de Secretariado Executivo Bilíngue sobre o cotidiano dos alunos, acredita-se que as informações poderão servir também como feedback para a própria instituição e para o corpo docente, na avaliação dos resultados do ano letivo em curso e planejamento do próximo período.

\section{MÉTODO DE PESQUISA}

Para efeito das investigações, optou-se pela pesquisa exploratória, não probabilística por conveniência, julgamento e cotas (BOYD E WESTEFALL, 1979, p. 398-399), porque a amostragem da pesquisa foi delimitada a partir da população representada pelos discentes do Curso de Secretariado Executivo Bilíngue em dois campi situados na cidade de São Paulo e dois campi no interior do estado, nas cidades de Sorocaba e São José dos Campos, considerando os alunos de primeiro e segundo semestres, no ano letivo de 2006.

A sondagem foi estruturada para ser recolhida em questionário individual, identificado (Apêndice $A$ ), onde os respondentes foram solicitados a considerar dez questões diretivas e uma não diretiva, possibilitando a obtenção de dados quantitativos e qualitativos, conforme ensina Barbetta (2005, p. 27-35).

A aplicação dos questionários deu-se em uma única vez, em sala de aula, considerando os alunos presentes naquele momento, independente da quantidade de matriculados para cada sala, tendo-se obtido amostragem de 93\% da população selecionada.

O questionário, conforme indicado no Apêndice $A$, incluiu questões destinadas a verificar o provável progresso dos alunos no desenvolvimento profissional, acadêmico e pessoal.

A pesquisa leva em conta os resultados obtidos nas respostas dos alunos, 
tendo as recomendações das diretrizes curriculares do MEC como parâmetro, ao estabelecer as competências do IES.

Compete ao IES a escolha estratégica das competências específicas que deverão ser desenvolvidas com o intuito de consolidar o perfil de egresso pretendido pelo curso e/ou habilitação. As competências e habilidades específicas dependem da vocação regional em que se encontra localizado o curso. A escolha das competências e habilidades específicas pode ser resultante do perfil, da vocação regional e, ainda, da organização diferenciada do currículo do curso e/ou habilitação que engloba o projeto pedagógico. (ANDRADE, 1999, p.12).

\section{OS EFEITOS DO PRIMEIRO ANO DO CURSO DE SECRETARIADO EXECUTIVO BILÍNGUE SOBRE O COTIDIANO DOS ALUNOS}

As ideias surgem de insights que ocorrem em ambientes favoráveis e criativos. Conforme Bronson (1994, p. 21) "Criatividade é a exploração de possibilidades". Assim, de uma reunião onde são traçadas as metas para revisão do Projeto Pedagógico de Curso surge a ideia, sendo o desafio lançado em busca de parceiros curiosos, dispostos a iniciar um grupo de trabalho, a fim de explorar cientificamente a respeito dos efeitos do primeiro ano do curso de Secretariado Executivo Bilíngue sobre o cotidiano dos alunos. Vasconcelos (1999, p. 31) ensina que "a percepção de um pesquisador sobre a dificuldade que um grupo ou instituição tem e necessita de solução" se constitui no problema a ser investigado.

\footnotetext{
As Diretrizes Curriculares Nacionais concebem a formação de nível superior como um processo contínuo, autônomo e permanente, com uma sólida formação profissional fundamentada na competência teórico-prática, de acordo com o perfil do formando, adaptável às novas e emergentes demandas. (MOREIRA E OLIVEIRA, 2002, s/p),
}

Partindo deste pressuposto propõe-se verificar os efeitos múltiplos do curso sobre o cotidiano dos alunos, ao mesmo tempo em que, segundo os mesmos 
autores, a Instituição de Ensino Superior tem como meta "estimular os alunos a participarem das atividades complementares e extracurriculares". (MOREIRA \& OLIVEIRA, 2002, s/p).

\section{RELATÓRIO DA PESQUISA}

A pesquisa foi realizada entre os alunos dos campi Vergueiro, Chácara, Sorocaba e São José dos Campos, do primeiro ano de Secretariado Executivo Bilíngue, ano letivo de 2006. Do universo possível de 271 alunos, 253 responderam aos questionários, representando 93\% da população.

A primeira pergunta teve como objetivo identificar os indivíduos pesquisados e agrupá-los de modo a poder compreender melhor a composição da população. Considerando-se a distribuição por sexo, constatou-se que 99,2\% pertencem ao sexo feminino contra $0,8 \%$ do sexo masculino, ao passo que pela faixa etária há uma prevalência com $89,4 \%$ da população na faixa até 30 anos, conforme quadro 1 seguinte:

Quadro 1: Classificação dos entrevistados por gênero e idade 
Prováveis Influências do Primeiro Ano do Curso de Secretariado Executivo Bilíngue no Cotidiano dos Estudantes

\begin{tabular}{|l|c|c|c|c|c|c|c|c|c|c|}
\hline & \multicolumn{2}{|c|}{ Chácara Sto Antônio } & \multicolumn{2}{|c|}{ Sorocaba } & \multicolumn{2}{|c|}{ São José dos Campos } & \multicolumn{2}{|c|}{ Vergueiro } & \multicolumn{3}{|c|}{ TOTAL } \\
Qtd & $\%$ & Qtd & $\%$ & Qtd & \multicolumn{2}{c|}{ Qtd } & \multicolumn{2}{c|}{ Qtd } \\
\hline até 20 anos & 28 & 30,5 & 18 & 51,4 & 19 & 46,3 & 25 & 29,4 & 90 & 35,6 \\
\hline de 21 a 25 & 35 & 38 & 12 & 34,3 & 14 & 34,1 & 27 & 31,8 & 88 & 34,8 \\
\hline de 26 a 30 & 21 & 22,8 & 4 & 11,4 & 4 & 9,8 & 19 & 22,4 & 48 & 19 \\
\hline acima de 30 & 8 & 8,7 & 1 & 2,9 & 4 & 9,8 & 14 & 16,5 & 27 & 10,7 \\
\hline Total & 92 & 100 & 35 & 100 & 41 & 100 & 85 & 100 & 253 & 100 \\
\hline
\end{tabular}

\begin{tabular}{|l|c|c|c|c|c|c|c|c|c|c|}
\hline Feminino & 91 & 98,9 & 35 & 100 & 40 & 97,6 & 85 & 100 & 251 & 99,2 \\
\hline Masculino & 1 & 1,1 & 0 & 0 & 1 & 2,4 & 0 & 0 & 2 & 0,8 \\
\hline Total respondente & 92 & 100 & 35 & 100 & 41 & 100 & 85 & 100 & 253 & 100 \\
\hline
\end{tabular}

\begin{tabular}{|l|c|l|c|l|c|l|l|l|l|l|}
\hline Total matriculado & 100 & & 35 & & 42 & & 94 & & 271 & \\
\hline$\%$ de respondentes & 92 & & 100 & & 98 & & 90 & & 93 & \\
\hline
\end{tabular}

Fonte: Elaborado pelos autores com os resultados da pesquisa de campo.

Quando perguntados sobre o nível gerencial que operam nas organizações a maioria representada por 49,5\% informou trabalhar na função de estagiário, assistente ou secretário, enquanto que apenas 20,6\% estavam em funções de auxiliares de escritório, auxiliares administrativos e recepcionista, $13,4 \%$ não informaram e 16,5\% trabalhavam em funções diversas, com menor afinidade com o curso, conforme o quadro 2 :

Revista de Gestão e Secretariado, São Paulo, v. 1, n. 2, p. 53-77, jul./dez. 2010. 
Quadro 2: Ocupação profissional na data da entrevista.

\begin{tabular}{|c|c|c|c|c|c|c|c|c|c|c|}
\hline & \multicolumn{2}{|c|}{ Chácara Sto Antônio } & \multicolumn{2}{|c|}{ Sorocaba } & \multicolumn{2}{|c|}{ São José dos Campos } & \multicolumn{2}{|c|}{ Vergueiro } & \multicolumn{2}{|c|}{ TOTAL } \\
\hline & Qtd & $\%$ & Qtd & $\%$ & Qtd & $\%$ & Qtd & $\%$ & Qtd & $\%$ \\
\hline Estagiária & 17 & 18,5 & 4 & 11,4 & 9 & 22 & 18 & 21,2 & 48 & 19 \\
\hline Assistente & 13 & 14,1 & 2 & 5,7 & 1 & 2,4 & 14 & 16,5 & 30 & 11,9 \\
\hline Secretária & 12 & 13 & 4 & 11,4 & 6 & 14,6 & 25 & 29,4 & 47 & 18,6 \\
\hline Estudante & 8 & 8,7 & 3 & 8,6 & 6 & 14,6 & 1 & 1,2 & 18 & 7,1 \\
\hline Auxiliar de Escritório & 6 & 6,5 & 0 & 0 & 1 & 2,4 & 2 & 2,4 & 9 & 3,6 \\
\hline Recepcionista & 6 & 6,5 & 8 & 22,9 & 2 & 4,9 & 5 & 5,9 & 21 & 8,3 \\
\hline Aux. Administrativo & 3 & 3,3 & 5 & 14,3 & 6 & 14,6 & 8 & 9,4 & 22 & 8,7 \\
\hline Promotora & 2 & 2,2 & 3 & 8,6 & 1 & 2,4 & 2 & 2,4 & 8 & 3,2 \\
\hline Consultor & 2 & 2,2 & 0 & 0 & 0 & 0 & 0 & 0 & 2 & 0,8 \\
\hline Modelo & 1 & 1,1 & 0 & 0 & 0 & 0 & 0 & 0 & 1 & 0,4 \\
\hline Operador de Telemkt & 1 & 1,1 & 0 & 0 & 2 & 4,9 & 3 & 3,5 & 6 & 2,4 \\
\hline Gestor & 1 & 1,1 & 0 & 0 & 0 & 0 & 0 & 0 & 1 & 0,4 \\
\hline Outro & 0 & - & 1 & 2,9 & 1 & 2,4 & 4 & 4,7 & 6 & 2,4 \\
\hline Não declarou & 20 & 21,7 & 5 & 14,3 & 6 & 14,6 & 3 & 3,5 & 34 & 13,4 \\
\hline Total & 92 & 100 & 35 & 100 & 41 & 100 & 85 & 100 & 253 & 100 \\
\hline
\end{tabular}

Fonte: Elaborado pelos autores com os resultados da pesquisa de campo.

Ao procurar conhecer a base de formação dos alunos, $12,6 \%$ responderam já ter cursado, total ou parcialmente, outro curso superior, enquanto que para $86,6 \%$ esta é a primeira oportunidade de estar numa universidade, o que contribui para que o curso superior ganhe status e gere expectativas maiores para esse grupo, conforme demonstra o quadro 3 :

Quadro 3: Grau de expectativa

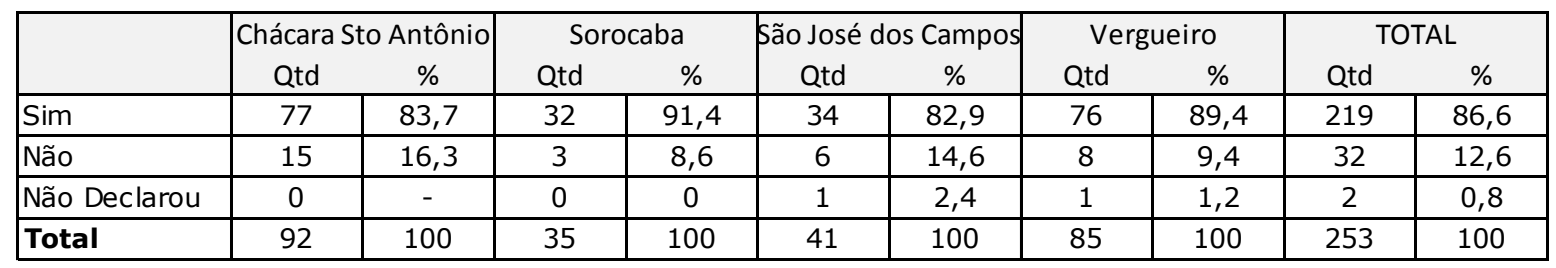

Fonte: Elaborado pelos autores com os resultados da pesquisa de campo.

O motivo que levou o aluno à escolha do curso, fator determinante da pesquisa, ofereceu alternativas de respostas com a finalidade de identificar o processo de opção e de decisão. Ficou demonstrada a tendência ao pragmatismo

Revista de Gestão e Secretariado, São Paulo, v. 1, n. 2, p. 53-77, jul./dez. 2010. 
da clientela, como forte indicador para o planejamento das ações pedagógicas dos professores, visto que $40,7 \%$ dos alunos informaram ter optado pelo curso por vocação e $37,6 \%$ por já atuarem na área. Uma pequena minoria, conforme o quadro 4 a seguir, disse ter escolhido o curso por outros motivos. No entanto, como será demonstrada mais adiante, a maioria dos alunos que se declaram insatisfeitos com a escolha são exatamente aqueles que declararam ter feito a opção por influência de familiares, que no caso chega a $11,5 \%$ da população investigada.

Quadro 4: Motivos que levaram os alunos a escolherem o curso de SEB

\begin{tabular}{|c|c|c|c|c|c|c|c|c|c|c|}
\hline & \multicolumn{2}{|c|}{ Chácara Sto Antônio } & \multicolumn{2}{|c|}{ Sorocaba } & \multicolumn{2}{|c|}{ São José dos Campos } & \multicolumn{2}{|c|}{ Vergueiro } & \multicolumn{2}{|c|}{ TOTAL } \\
\hline & Qtd & $\%$ & Qtd & $\%$ & Qtd & $\%$ & Qtd & $\%$ & Qtd & $\%$ \\
\hline Minha vocação & 34 & 37 & 15 & 42,9 & 16 & 39 & 38 & 44,7 & 103 & 40,7 \\
\hline $\begin{array}{l}\text { Já trabalho na área } \\
\text { e o curso pode me } \\
\text { ajudar na carreira. }\end{array}$ & 35 & 38 & 11 & 31,4 & 13 & 31,7 & 36 & 42,4 & 95 & 37,6 \\
\hline $\begin{array}{l}\text { Por influência de } \\
\text { familiares }\end{array}$ & 9 & 9,8 & 8 & 22,9 & 5 & 12,2 & 7 & 8,2 & 29 & 11,5 \\
\hline $\begin{array}{l}\text { Por influência de } \\
\text { amigos }\end{array}$ & 6 & 6,5 & 1 & 2,9 & 4 & 9,8 & 2 & 2,4 & 13 & 5,1 \\
\hline Outros & 1 & 1,1 & 0 & 0 & 0 & 0 & 0 & 0 & 1 & 0,4 \\
\hline Não Declarou & 7 & 7,6 & 0 & 0 & 3 & 7,3 & 2 & 2,4 & 12 & 4,7 \\
\hline Total & 92 & 100 & 35 & 100 & 41 & 100 & 85 & 100 & 253 & 100 \\
\hline
\end{tabular}

Fonte: Elaborado pelos autores com os resultados da pesquisa de campo.

Ao investigar a respeito da condição de emprego da população representada pelos alunos do primeiro ano de Secretariado Executivo Bilíngue, turma 2006 , observou-se que $66,4 \%$ se encontravam empregados no início do ano contra $32 \%$ que se encontravam desempregados e $1,6 \%$ que não declarou (quadro 5).

Quadro 5: Condição de empregos dos entrevistados

\begin{tabular}{|l|c|c|c|c|c|c|c|c|c|c|}
\hline & \multicolumn{2}{|c|}{ Chácara Sto Antônio } & \multicolumn{2}{|c|}{ Sorocaba } & \multicolumn{2}{|c|}{ São José dos Campos } & \multicolumn{2}{c|}{ Vergueiro } & \multicolumn{3}{c|}{ TOTAL } \\
& Qtd & $\%$ & Qtd & $\%$ & Qtd & \multicolumn{2}{c|}{ Qtd } & Qtd & \multicolumn{2}{c|}{$\%$} \\
\hline Sim & 64 & 69,6 & 21 & 60 & 17 & 41,5 & 66 & 77,6 & 168 & 66,4 \\
\hline Não & 26 & 28,3 & 14 & 40 & 23 & 56,1 & 18 & 21,2 & 81 & 32 \\
\hline Não Declarou & 2 & 2,1 & 0 & 0 & 1 & 2,4 & 1 & 1,2 & 4 & 1,6 \\
\hline Total & 92 & 100 & 35 & 100 & 41 & 100 & 85 & 100 & 253 & 100 \\
\hline
\end{tabular}

Fonte: Elaborado pelos autores com os resultados da pesquisa de campo.

Revista de Gestão e Secretariado, São Paulo, v. 1, n. 2, p. 53-77, jul./dez. 2010. 
Determinado o perfil da clientela que chegou às salas de aula no início do ano, buscou-se aferir as condições em que a mesma população se encontrava no final de 2006, entre novembro e dezembro, no período da realização das provas do segundo semestre e dos exames finais.

A primeira pergunta do bloco buscava aferir, por meio de oito alternativas " 0 que aconteceu com a sua carreira profissional neste primeiro ano do curso de Secretariado Executivo Bilíngue e suas projeções para o futuro", tendo obtido as respostas relacionadas no quadro 6, com maior frequência para o progresso profissional, verificou-se que $18,2 \%$ conseguiram estágios; $16,2 \%$ mudaram de empregos para posições e salários melhores; $24,9 \%$ se consideram em vias de ser promovido e $12,3 \%$ foram reconhecidos no próprio trabalho com promoções ou aumentos de salários e as consequentes mudanças de funções.

Quadro 6: Mudança profissional durante $01^{\circ}$ ano do curso

Revista de Gestão e Secretariado, São Paulo, v. 1, n. 2, p. 53-77, jul./dez. 2010. 


\begin{tabular}{|c|c|c|c|c|c|c|c|c|c|c|}
\hline & Chácara & Antônio & & & São Jose & Campos & & iro & & \\
\hline & Qtd & $\%$ & Qtd & $\%$ & Qtd & $\%$ & Qtd & $\%$ & Qtd & $\%$ \\
\hline \begin{tabular}{|l|}
$\begin{array}{l}\text { Consegui meu primeiro } \\
\text { estágio. }\end{array}$ \\
\end{tabular} & 11 & 12 & 5 & 14,3 & 13 & 31,7 & 17 & 20 & 46 & 18,2 \\
\hline $\begin{array}{l}\text { Consegui meu primeiro } \\
\text { emprego efetivo. }\end{array}$ & 5 & 5,4 & 1 & 2,9 & 3 & 7,3 & 1 & 1,2 & 10 & 4 \\
\hline $\begin{array}{l}\text { Mudei de emprego para } \\
\text { posição e cargo iguais } \\
\text { aos anteriores. }\end{array}$ & 3 & 3,3 & 0 & 0 & 1 & 2,4 & 1 & 1,2 & 5 & 2 \\
\hline $\begin{array}{l}\text { Mudei de emprego para } \\
\text { posição e cargo } \\
\text { melhores, inclusive } \\
\text { com salário melhor. }\end{array}$ & 19 & 20,6 & 4 & 11,4 & 2 & 4,9 & 16 & 18,8 & 41 & 16,2 \\
\hline \begin{tabular}{|l|} 
Ainda não fui \\
promovido, mas \\
aparentemente tenho \\
grandes chances no \\
mesmo emprego em \\
que me encontrava \\
desde o início do ano.
\end{tabular} & 19 & 20,6 & 7 & 20 & 7 & 17,1 & 30 & 35,3 & 63 & 24,9 \\
\hline \begin{tabular}{|l|} 
Já fui reconhecido e \\
promovido no mesmo \\
emprego em que me \\
encontrava desde o \\
início do ano. \\
\end{tabular} & 12 & 13 & 6 & 17,1 & 2 & 4,9 & 11 & 12,9 & 31 & 12,3 \\
\hline $\begin{array}{l}\text { Deixei o emprego que } \\
\text { tinha e procuro uma } \\
\text { nova colocação. }\end{array}$ & 6 & 6,5 & 3 & 8,6 & 4 & 9,8 & 3 & 3,5 & 16 & 6,3 \\
\hline $\begin{array}{l}\text { Perdi o emprego e } \\
\text { estou tentando uma } \\
\text { nova colocação. } \\
\end{array}$ & 9 & 9,8 & 0 & 0 & 0 & 0 & 0 & 0 & 9 & 3,6 \\
\hline Não declarou & 8 & 8,8 & 9 & 25,7 & 9 & 22 & 6 & 7,1 & 32 & 12,6 \\
\hline Total & 92 & 100 & 35 & 100 & 41 & 100 & 85 & 100 & 253 & 100 \\
\hline
\end{tabular}

Fonte: Elaborado pelos autores com os resultados da pesquisa de campo.

\section{Sobre as expectativas futuras quanto ao mercado de trabalho e a} aferir a tendência ao empreendedorismo, os alunos reconhecem a dinâmica do ambiente econômico e declaram abertamente a preocupação com a necessidade de especialização e atualização permanente para a ocupação dos postos de trabalho. Apenas $4,7 \%$ dos entrevistados vislumbram oportunidades de desenvolvimento de atividades independentes como a terceirização de serviços ou a realização de eventos. (quadro 7)

Revista de Gestão e Secretariado, São Paulo, v. 1, n. 2, p. 53-77, jul./dez. 2010. 
Quadro 7: Necessidades e Perspectivas

\begin{tabular}{|c|c|c|c|c|c|c|c|c|c|c|}
\hline & \multicolumn{2}{|c|}{ Chácara Sto Antônio } & \multicolumn{2}{|c|}{ Sorocaba } & \multicolumn{2}{|c|}{ São José dos Campos } & \multicolumn{2}{|c|}{ Vergueiro } & \multicolumn{2}{|c|}{ TOTAL } \\
\hline & Qtd & $\%$ & Qtd & $\%$ & Qtd & $\%$ & Qtd & $\%$ & Qtd & $\%$ \\
\hline $\begin{array}{l}\text { Pretendo ser independente e montar } \\
\text { meu próprio escritório de consultoria na } \\
\text { área de secretariado. }\end{array}$ & 5 & 5,4 & 2 & 5,7 & 3 & 7,3 & 2 & 2,4 & 12 & 4,7 \\
\hline $\begin{array}{l}\text { Pretendo trabalhar sempre como } \\
\text { empregado por ser menos arriscado. }\end{array}$ & 1 & 1,1 & 0 & 0 & 2 & 4,9 & 3 & 3,5 & 6 & 2,4 \\
\hline Pretendo mudar de área. & 13 & 14,1 & 1 & 2,9 & 4 & 9,8 & 1 & 1,2 & 19 & 7,5 \\
\hline $\begin{array}{l}\text { Pretendo especializar-me mais na área } \\
\text { para alcançar um diferencial nessa } \\
\text { profissão. }\end{array}$ & 52 & 56,6 & 24 & 68,6 & 23 & 56,1 & 60 & 70,6 & 159 & 62,9 \\
\hline
\end{tabular}

Fonte: Elaborado pelos autores com os resultados da pesquisa de campo.

O módulo seguinte se propôs a verificar o grau de satisfação dos alunos com o curso escolhido e as suas contribuições para o aproveitamento do conteúdo lecionado e o andamento da programação no ano letivo. 0 quadro 8 mostra a percepção declarada dos alunos quanto às informações gerais do curso, dando a indicação de satisfação. É interessante a constatação de que $41,5 \%$ declaram que poderiam ter aproveitado mais e $4 \%$ se declaram insatisfeitos. Ao individualizar as respostas, é possível verificar que os insatisfeitos, em geral, decidiram pelo curso por influência familiar.

Quadro 8: Satisfação dos alunos com o curso escolhido.

\begin{tabular}{|l|c|c|c|c|c|c|c|c|c|c|}
\hline & \multicolumn{2}{|c|}{ Chácara Sto Antônio } & \multicolumn{2}{|c|}{ Sorocaba } & \multicolumn{2}{|c|}{ São José dos Campos } & \multicolumn{2}{c|}{ Vergueiro } & \multicolumn{3}{c|}{ TOTAL } \\
\cline { 2 - 13 } & Qtd & $\%$ & Qtd & $\%$ & Qtd & $\%$ & Qtd & $\%$ & Qtd & $\%$ \\
\hline $\begin{array}{l}\text { Estou satisfeito, acho que fiz a } \\
\text { escolha certa e pude melhorar. }\end{array}$ & 47 & 51,1 & 14 & 40 & 22 & 53,7 & 49 & 57,6 & 132 & 52,2 \\
\hline $\begin{array}{l}\text { Estou satisfeito, mas poderia } \\
\text { ter aproveitado mais. }\end{array}$ & 40 & 43,5 & 18 & 51,4 & 12 & 29,3 & 35 & 41,2 & 105 & 41,5 \\
\hline $\begin{array}{l}\text { Não estou satisfeito, acho que } \\
\text { fiz a escolha errada. }\end{array}$ & 2 & 2,2 & 2 & 5,7 & 5 & 12,2 & 1 & 1,2 & 10 & 4 \\
\hline Não Declarou & 3 & 3,2 & 1 & 2,9 & 2 & 4,9 & 0 & 0 & 6 & 2,4 \\
\hline Total & 92 & 100 & 35 & 100 & 41 & 100 & 85 & 100 & 253 & 100 \\
\hline
\end{tabular}

Fonte: Elaborado pelos autores com os resultados da pesquisa de campo.

$\mathrm{Na}$ tentativa de aferir as influências do curso sobre o comportamento dos alunos, quanto à postura e atitudes em relação à profissão e ao mercado de trabalho foi perguntado: "Você acha que o primeiro ano do curso de SEB

Revista de Gestão e Secretariado, São Paulo, v. 1, n. 2, p. 53-77, jul./dez. 2010. 
ofereceu condições e elementos para seu comportamento, sua postura e suas atitudes em relação ao trabalho e à vida profissional?". A esmagadora maioria de 92,9\% afirma que "sim" contra 6,7\% que afirmam "não", como se pode verificar no Quadro 9.

Quadro 9: Influências do curso no comportamento profissional dos alunos

\begin{tabular}{|l|c|c|c|c|c|c|c|c|c|c|c|}
\hline & \multicolumn{2}{|c|}{ Chácara Sto Antônio } & \multicolumn{2}{c|}{ Sorocaba } & São José dos Campos & \multicolumn{2}{c|}{ Vergueiro } & \multicolumn{2}{c|}{ TOTAL } \\
\cline { 2 - 14 } & Qtd & $\%$ & Qtd & $\%$ & Qtd & $\%$ & Qtd & $\%$ & Qtd & $\%$ \\
\hline Sim & 84 & 91,3 & 33 & 94,3 & 37 & 90,2 & 81 & 95,3 & 235 & 92,9 \\
\hline Não & 7 & 7,6 & 2 & 5,7 & 4 & 9,8 & 4 & 4,7 & 17 & 6,7 \\
\hline Não Declarou & 1 & 1,1 & 0 & 0 & 0 & 0 & 0 & 0 & 1 & 0,4 \\
\hline Total & 92 & 100 & 35 & 100 & 41 & 100 & 85 & 100 & 253 & 100 \\
\hline
\end{tabular}

Fonte: Elaborado pelos autores com os resultados da pesquisa de campo.

Ainda, ao aferir a disponibilidade e a voluntariedade dos alunos em relação ao curso e às disciplinas, foi perguntado: "Você tem se limitado a assistir às aulas e às informações passadas em sala de aula?" (quadro 10) e a maioria, representada por 58,1\%, respondeu que "não", enquanto que 40,3\% responderam que sim.

Quadro 10: Limitação aos conteúdos ministrados em salas de aulas

\begin{tabular}{|l|c|c|c|c|c|c|c|c|c|c|c|}
\hline & \multicolumn{2}{|c|}{ Chácara Sto Antônio } & \multicolumn{2}{c|}{ Sorocaba } & \multicolumn{2}{c|}{ São José dos Campos } & \multicolumn{2}{c|}{ Vergueiro } & \multicolumn{2}{c|}{ TOTAL } \\
\cline { 2 - 13 } & Qtd & $\%$ & Qtd & $\%$ & Qtd & $\%$ & Qtd & $\%$ & Qtd & $\%$ \\
\hline Sim & 38 & 41,3 & 18 & 51,4 & 25 & 61 & 21 & 24,7 & 102 & 40,3 \\
\hline Não & 51 & 55,4 & 17 & 48,6 & 16 & 39 & 63 & 74,1 & 147 & 58,1 \\
\hline Não Declarou & 3 & 3,3 & 0 & 0 & 0 & 0 & 1 & 1,2 & 4 & 1,6 \\
\hline Total & 92 & 100 & 35 & 100 & 41 & 100 & 85 & 100 & 253 & 100 \\
\hline
\end{tabular}

Fonte: Elaborado pelos autores com os resultados da pesquisa de campo.

Na pergunta seguinte: "Você tem extrapolado e procurado se manter informado(a) por meio de leituras e pesquisas complementares no sentido de atingir metas e objetivos?" (quadro 11) foram sugeridas algumas formas de estudos complementares e a proporção de respostas "sim" foi de $70,8 \%$, demonstrando alguma contradição entre os respondentes em razão dos percentuais díspares aferidos, mas confirmando que a maioria declarou não se

Revista de Gestão e Secretariado, São Paulo, v. 1, n. 2, p. 53-77, jul./dez. 2010. 
limitar às salas de aulas e a realizar pesquisas complementares, um fato positivo para efeito de planejamento de atividades futuras.

Quadro 11: Estudos e pesquisas fora da sala de aula

\begin{tabular}{|l|c|c|c|c|c|c|c|c|c|c|}
\hline & \multicolumn{2}{|c|}{ Chácara Sto Antônio } & \multicolumn{2}{|c|}{ Sorocaba } & \multicolumn{2}{c|}{ São José dos Campos } & \multicolumn{2}{c|}{ Vergueiro } & \multicolumn{2}{c|}{ TOTAL } \\
\cline { 2 - 13 } & Qtd & $\%$ & Qtd & $\%$ & Qtd & $\%$ & Qtd & $\%$ & Qtd & $\%$ \\
\hline Sim & 64 & 69,6 & 25 & 71,4 & 24 & 58,5 & 66 & 77,6 & 179 & 70,8 \\
\hline Não & 27 & 29,3 & 9 & 25,7 & 17 & 41,5 & 19 & 22,4 & 72 & 28,5 \\
\hline Não Declarou & 1 & 1 & 1 & 2,9 & 0 & 0 & 0 & 0 & 2 & 0,8 \\
\hline Total & 92 & 100 & 35 & 100 & 41 & 100 & 85 & 100 & 253 & 100 \\
\hline
\end{tabular}

Fonte: Elaborado pelos autores com os resultados da pesquisa de campo.

Finalmente, para questão aberta: "Faça seus comentários pessoais ou acrescente informações que não foram perguntadas e que você acha relevantes para o desenvolvimento deste assunto", os alunos que responderam, cerca de 30\%, ficaram entre elogios ao curso, comentários a respeito do conteúdo, manifestação de expectativas pessoais e queixas relacionadas às divergências entre as expectativas e o conteúdo esperado e o conteúdo apresentado na matriz curricular, sugerindo que o curso, em sua totalidade deve ser mais bem explicado aos alunos logo na apresentação, indicando, inclusive, o ritmo de transferência do conhecimento. Há, aparentemente, forte expectativa e frustração a respeito do quesito idiomas estrangeiros, ensejando alguma atuação no sentido de identificar as anomalias e aplicar as medidas corretivas cabíveis, de implementação ou de comunicação.

\section{CONSIDERAÇÕES FINAIS}

Os dados levantados na pesquisa permitem concluir que os alunos que participaram da pesquisa e frequentam o curso de Secretariado Executivo Bilíngue, estão satisfeitos com o conteúdo e com os resultados que vêm alcançando a partir das informações obtidas em sala de aula, do ponto de vista teórico e prático e das influências relativas ao suporte pessoal, quanto ao 
comportamento, às atitudes e à postura diante do mercado de trabalho.

Trata-se de uma clientela heterogênea tanto no que se refere à origem quanto às expectativas conforme se observa pelas respostas e até pela experiência de convívio acadêmico com o grupo.

São pessoas com objetivos bem definidos e dispostas a empenhar os esforços necessários para acompanhar os eventos, tendência que cresce na medida em que os resultados práticos começam a aparecer em sala de aula com os comentários a respeito da movimentação social e profissional decorrente do curso, conforme a própria pesquisa materializou.

O cenário é próprio para que a escola desenvolva propostas complementares e sugere, também, que os professores podem associar ao conteúdo acadêmico alguma dose de experiências práticas acrescidas de atividades multidisciplinares complementares.

A análise mais aprofundada dos desvios da pesquisa indica oportunidades onde os professores podem incluir melhorias nas aulas e na forma de se conduzir com relação à escolha e à transmissão dos conteúdos.

Embora esta análise tenha se fixado nos dados consolidados de todos os campi, preservaram-se os dados de cada campus para que os professores, observando os pressupostos de avaliação sugeridos pelo MEC, possam avaliar e comparar suas unidades tendo em vista as características regionais para aferir suas próprias conclusões.

Finalmente, identifica-se que os alunos embora conscientes de suas limitações e dificuldades, têm esperança no futuro, sabem da importância da formação acadêmica em suas vidas e estão certos de que continuarão tendo de se superar em cada tarefa, mas não abrem mão dessa oportunidade.

A escola, por seu turno, pode aferir positivamente os resultados práticos de sua atividade pela promoção intelectual e social de seus alunos que se transformam em agentes de mudança, beneficiando e sendo beneficiados pela aplicação do conhecimento ao mesmo tempo em que se tornam reeditores de processos e influenciam os microambientes familiares e profissionais com os 
quais interagem.

Do lado dos professores, cabe a tarefa de se empenhar para manter alto o entusiasmo dos alunos e criar condições que facilitem a aprendizagem e a promoção dessas pessoas na busca da realização de seus projetos pessoais, fruto de suas decisões que serão concretizadas por meio de seus comportamentos, suas atitudes e posturas diante dos desafios do cotidiano.

O estudo identificou influências positivas do primeiro ano do curso de secretariado no cotidiano dos alunos no sentido de ajudar criar condições para a consecução do primeiro emprego (18,2\% dos entrevistados), mudança de emprego para posição e cargo melhores $(16,2 \%$ dos entrevistados) e reconhecimento e promoção no mesmo emprego (12,3\%). Considerando-se o conjunto das influências positivas, tem-se que $46,7 \%$ dos entrevistados foram impactados no seu cotidiano por benefícios proporcionados pelo primeiro ano do curso de secretariado executivo bilíngue. Além desses benefícios patentes observou-se que $24,9 \%$ dos entrevistados perceberam que suas oportunidades de promoção aumentaram sensivelmente depois de concluído o primeiro ano.

\section{REFERÊNCIAS}

ALONSO, M. E. C. A arte de assessorar executivos. São Paulo: Edições Pulsar, 2002.

ALVES, R. Não é próprio falar de alunos... Disponível em: http://aprendiz.uol.com.br/content.view.action?uuid=9d0100be0af47010014098 4b8af8a369. Acesso em 15/7/2007.

ANDRADE, R. O. B. de (Coord.). Diretrizes curriculares para os cursos de graduação em administração (proposta). Brasília: MEC-SESU-DEPES-CEEAD, 1999. Disponível em: Http://www.fecap.br/facesp/professores/jaime/. Consulta em 21 out. 2002.

BARBETTA, P. A. Estatística aplicada às Ciências Sociais. $5^{\mathrm{a}}$ ed. rev. Florianópolis: Ed. da UFSC, 2005. 340p.

BARDWICK, J. M. Perigo na zona de conforto - Como eliminar o hábito do entitlement. 2at. São Paulo: Pioneira, 1998. 156p.

Revista de Gestão e Secretariado, São Paulo, v. 1, n. 2, p. 53-77, jul./dez. 2010. 
BARNARD, C. I. As funções do executivo. São Paulo: Atlas, 1971. 322p.

BOYD Jr, H. W. WESTFALL, R. Pesquisa Mercadológica. 4a ed. Rio de Janeiro: FGV, 1979. 803p.

BRONSON, H. Boa Ideia! E agora? Como transformar sua ideia, invenção ou negócio em um sucesso garantido. Rio de Janeiro: Record, 1994. 142p.

GENGHINI, L. A.; DERITO, E. R.. Markenting interno, endomarketing e endocomunicação. Revista Álvares Penteado, n. 10, vol.4, dezembro/2002, p. 67-74.

GIL, A. C. Metodologia do ensino superior. 2a ed. São Paulo: Atlas, 1994, 112p.

Júlio, C. A. Reinventando você. A dinâmica dos profissionais e a nova organização. Rio de Janeiro: Campus, 2002. 203p.

MACEDO, R. Seu diploma, sua prancha - como escolher a profissão e surfar no mercado de trabalho. São Paulo: Saraiva, 1998. 260p.

MATTAR, M. E. Qualificação profissional: Uma atividade que dá trabalho. Revista RETS [On Line]. 18 de outubro 2002. Disponível em: http://tamarindo.rits.org.br/notitia/servlet/. Acesso em 21/10/2002.

MOREIRA, D. A.; OLIVEIRA, T. V de. Preditores precoces de analfabetismo funcional. Revista Administração On Line[On Line]. FECAP, n. 2, vol.3, abril, maio, junho-2002. Disponível em: http://www.fecap.br/adm_online/. Acesso em $17 / 10 / 2002$.

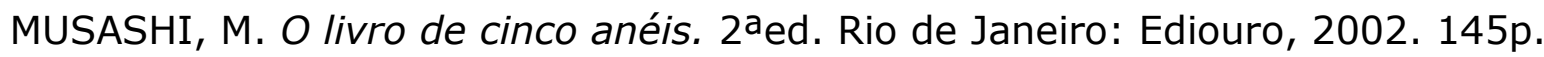

OLSEN, E. Mudanças - 12 passos para administrá-las sem prejudicar os seus negócios. São Paulo: Siciliano, 1994. 251p.

RIFKIN, J. O século da biotecnologia. São Paulo: Makron Books, 1999. 292p.

SHINYASHIKY, R. Você a alma do negócio. São Paulo: Gente, 2001. 174p.

SLATER, D. Cultura do consumo e modernidade. São Paulo: Nobel, 2002. 216p.

VASCONCELOS, N.P. Manual para edição de trabalhos acadêmicos. São Paulo: Café Editora Expressa, 1999. 220p. 
Apêndice A: Questionário Individual

\begin{tabular}{|c|c|}
\hline Item & Assunto da questão \\
\hline 1 & Qualificação dos respondentes \\
\hline 2 & $\begin{array}{l}\text { A Faculdade de Secretariado Executivo Bilíngue (SEB) é o primeiro curso } \\
\text { superior que você está cursando? } \\
\text { SIM_ NÃO_ }\end{array}$ \\
\hline 3 & $\begin{array}{l}\text { Por que você está cursando SEB, ou qual o motivo que influenciou na } \\
\text { escolha do curso de Secretariado Executivo Bilíngue? } \\
\text { Minha vocação. } \\
\text { _ Já trabalho na área e o curso pode me ajudar na carreira. } \\
\text { Por influência de familiares. } \\
\text { Por influência de amigos. }\end{array}$ \\
\hline 4 & $\begin{array}{l}\text { No início do ano, quando iniciou o curso, você estava empregado(a)? } \\
\text { SIM_ }\end{array}$ \\
\hline 5 & $\begin{array}{l}\text { O que aconteceu com sua carreira profissional neste primeiro ano do curso } \\
\text { de SEB e quais são as suas projeções para o futuro. } \\
\text { Consegui meu primeiro estágio. } \\
\text { Consegui meu primeiro emprego efetivo. } \\
\text { Mudei de emprego para posição e cargos iguais aos anteriores. } \\
\text { salário melhor. } \\
\text { chudei de emprego para posição e cargos melhores, inclusive com } \\
\text { ences no mesmo emprego em que me encontrava desde o início do ano. } \\
\text { entrava desde o início do ano. } \\
\text { Deixei o emprego que tinha e procuro uma nova colocação. } \\
\text { Perdi o emprego e estou tentando uma nova colocação. }\end{array}$ \\
\hline 6 & $\begin{array}{l}\text { E a respeito de seu futuro profissional? } \\
\text { No futuro pretendo ser independente e montar meu próprio } \\
\text { escritório de consultoria na área de secretariado. } \\
\text { arriscado. }\end{array}$ \\
\hline & Pretendo diversificar minha maneira de trabalho, já que as \\
\hline
\end{tabular}

Revista de Gestão e Secretariado, São Paulo, v. 1, n. 2, p. 53-77, jul./dez. 2010. 


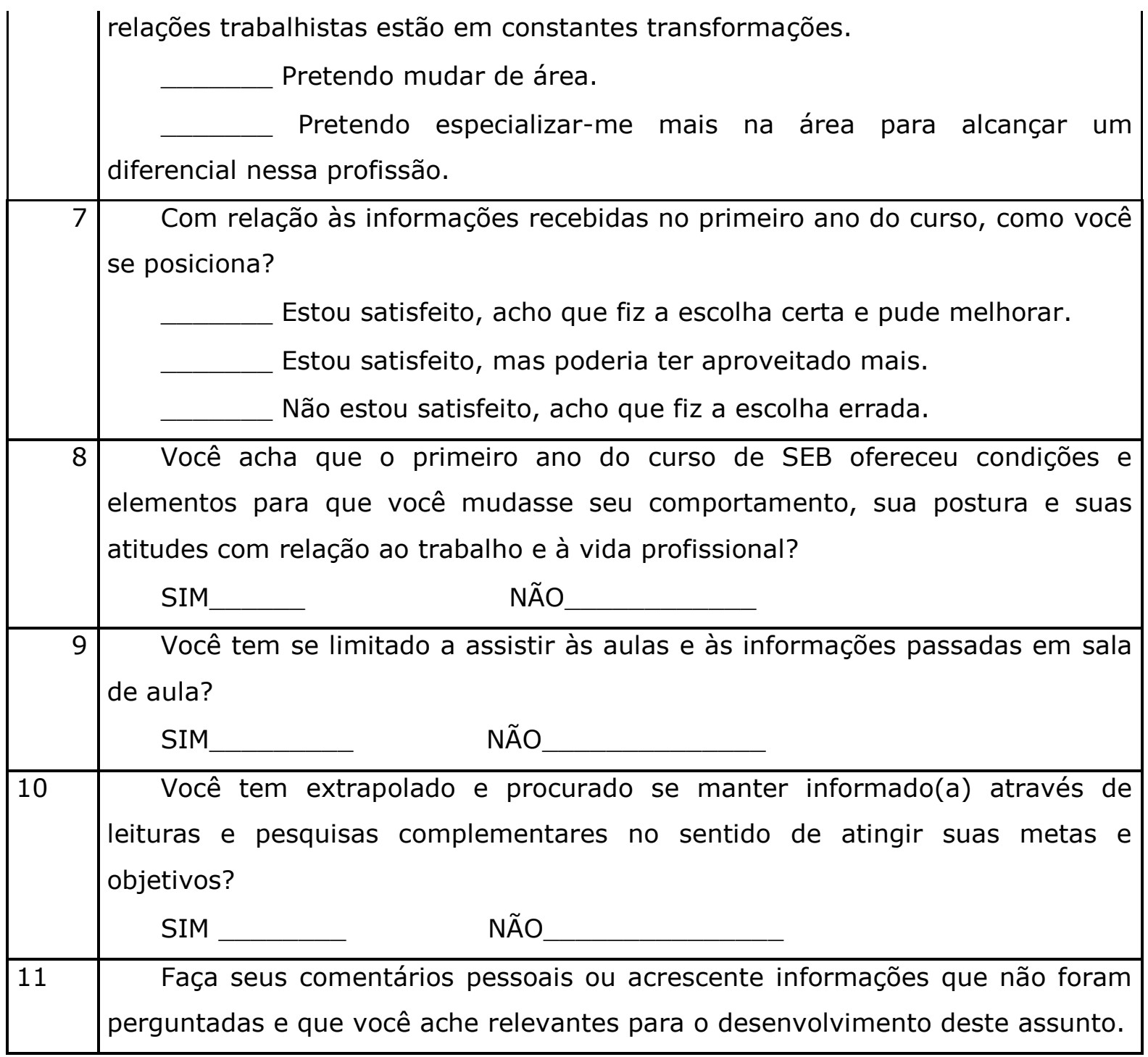

Fonte: Elaborado pelos autores.

Revista de Gestão e Secretariado, São Paulo, v. 1, n. 2, p. 53-77, jul./dez. 2010. 